rent is slackened by striking the ocean where a shoal is forming.

Since the formation of these marshes the beaches, by the action of wind and wave, have been moving inland. Inlets are becoming shallower, and the beaches, in places, have been completely blown from their original bed over on to the marshes, so that the marsh mud is often exposed on the ocean side.

This accounts for the size which the trees attain in these places. Many beaches support only a shrubby vegetation, others are covered with beautiful forests of trees of surprising size. Red cedar, holly, sassafras, oak, liquid amber, sour gum, magnolia, sweetgale and grape vines grow to be unusually large. Some of the finest specimens of holly in existence may be found on several of these beaches, and the red cedar which grows there is more durable than that of the mainland. The size of these trees is due to the fact that their roots have penetrated through the sand of the beach into the rich, black mud of the marsh beneath.

These forests are doomed. The wind picks up the fine white sand of the beach and piles it in dunes. These are often as high as the tree tops and are moving gradually inland, leaving only a mass of dark gray trunks behind. Unfortunately the trees themselves prevent the west and and north winds from blowing back the sand.

The fact that Jersey is slowly sinking complicates these changes. The marshes, in consequence, are intruding upon the mainland. Even white cedars, which only grow in pure fresh water, have been found buried in the marsh. Little islands and Indian shell heaps are slowly disappearing.

In the formation of these marshes organic agencies play an important part. An examination of the mud in shallow bays and salt ponds shows enormous quantities of beautiful diatoms. There, too, are many kinds of shells. Other animals, especially those of the crab tribe, completely honeycomb the marsh in places.

These meadows are very rich and valuable for farming. When banked and sluiced, although they shrink, they freshen and, after being worked for a time, yield enormous crops. In several places in South Jersey they have been converted into flourishing farms. In other places up the rivers they have been abandoned because of the muskrats which undermine the banks.

These vast stretches of marsh are richly colored, and at times, in places, are covered with white, pink and yellow flowers. They are alive, in season, with wild migratory water-fowl, infested with flies and mosquitoes and flecked with the sails of boats moving in the creeks and bays. In winter they are deserted and dreary, the monotony of which is only broken by a hay or fish house here and there or the remnants of a stranded schooner.

The collecting of the hay which grows on the marshes is one of the leading industries of that part of the state. It is still, in many places, cut with the scythe and carried on hand poles to large clumsy scows, which are rowed with two long oars to the landings.

There are 300,000 acres of marsh region in South Jersey. At least one-twentieth of this is cut for hay. An acre yields, without sowing or care, other than a little ditching, at times, and burning once a year, at least one and a half tons. The many creeks which bend in every direction render it easy of access. It is worth at least six dollars a ton. The annual crop is worth then not a cent less than $\$ 135,000$.

The marshes are often too soft for horses; in places they are provided with wooden shoes, and many meadows are hard enough for the use of machines.

This hay is often baled and shipped away. The greater part is consumed at home. Poor qualities are used by glass factories for packing purposes.
The two plants of greatest value yielding hay on these marshes are Spartina juncea or "salt-hay" and Juncus gerardi or "black-grass." The one is a true grass, the other a rush. The salt hay is light in color, contains few seeds, is cut late in summer and is fed to horses. The black grass grows in brackish regions, is full of seeds, is dark in color, is cut in mid-summer and is fed to cattle.

If reclaimed on a very large scale, as in Louisiana, the writer believes that these marshes may and will soon be converted into flourishing farms.

\section{METHODS OF PRESENTING GEOLOGY IN OUR SCHOOLS AND COLLEGES.*}

BY MISS MARY E. HOLMES, PH.D., ROCKFORD, ILL.

BEFORE offering any suggestions as to "methods" of presenting this study, let us state a few axioms:

First. For the successful study of any subject there must be some foundation.

Second. Comparatively few of our high school pupils enter college.

Third. The large majority of school age will not advance beyond the grammar grade.

Fourth. The impressions earliest made are most enduring.

Fifth. If we would make geology a life force, a life inspiration to the masses generally and to those in our high schools and colleges, we must begin with the little children.

How early a child's attention may be profitably called to the elements of geology may be questioned, but I think as soon as he can talk, and understand what is said to him. Of course the first lessons will be very, very simple-mostly in form and color. He will gladly gather for you the "pitty stones," and you will notice that these, gathered by himself, and when alone, are generally either definitely colored, or smooth rounded ones, or smooth flattened ones, few being angular. With your aid let him separate the rounded from fiattened, calling his attention to the difference in shape. Mix them and separate again. Repeat the process many times, at first always letting the child hand you the stones, you frequently asking: "Where shall we place this one?" Later, let him place them himself. In a few days he will have so mastered the distinction between flat and round, that he can separate quite correctly a large pile. Never continue the lessons till he is weary. When such signs appear suggest that he run out doors and play. In all probability he will return with another pocketful of stones. Appear pleased with his acquisitions and be pleased. He will detect any insincerity. Give him a box, or a low shelf of his very own for his treasures. With encouraging words, the child will thus spend many hours ; they are not play, nor work, but happy, instructive seasons.

Having learned to separate round from flattened stones, call his attention to rough, angular forms. He will quickly note the difference. Show him that these are angular because broken from a larger stone. Illustrate by some broken toy of his own. Also show him how to make more angular ones by cracking these with a hammer. If he pounds his fingers, a little experience will remedy that as a frequent future result. He cannot appreciate the smoothing effect of water, so pass it by. Many lessons upon surfaces may be received unconsciously in this way, the child learning how to use his eyes, and to compare one object with another.

Next, take the colors of the stones. Separate them into piles, dark and light. Separate again the blackish, the red-

* A paper read before the Woman's Department in Geology in the World's Congress Auxiliary of the World's Columbian Exposition at Chicago, August 21, I8g2. 
dish, the gray and the white. Do it with him many times, but each time he will do it more and more himself, till he accomplishes it alone. Should any pebble have a hole in it, or any special feature, his eye and finger"wiil be sure to find it, and an exclamation will burst forth: "See!" $\mathrm{He}$ has discovered something. He now looks for more, like, or similar to it.

Next, teach him to select them according to lustre, if in a vicinity where micaceous or other specially lustrous rocks are frequent. If not, as a special privilege, let him wet some in a bowl of water while the others are dry. The difference he quickly sees, and next time, if no water is at hand, he will be more than apt to wet them with his tongue, and exclaim again "See!" his tone and look indicating that he recognizes an effect upon the stone like that produced before by the water. Here he has really learned that one general agent, under two forms, from two different sources may produce a similar effect. As to kinds of lustre, he may be readily trained to recognize pearly, like the inside of the shell on the mantel, and glassy; also that the absence of lustre is dull. Of degrees, he can comprehend shining and glistening, and learn the words as well. A child does not need such short words as we often think. $\mathrm{He}$ delights in mastering a "big word," if only for the protracted sound, but if it conveys a pleasant thought, his interest is greatly intensified.

Next, teach hardness by rubbing two stones together, and by letting him try to scratch them; first with a nail, and second with a sharp-edged piece of quartz or fint. $\mathrm{He}$ can make perhaps three piles-those soft, easily scratched with anything; those harder, only scratched with the nail and quartz, and those hardest, not scratched by the nail, but by the quartz. These distinctions are crude, but real, to the child that recognizes them.

What has been thus pursued from day to day in the realm of stones, if the mother or kindergartner is wise, should have been carried on also with plants, insects, and birds, even some lessons on the "twinkling stars." Of these, botany, zoölogy, and astronomy, we do not now speak, but, be it remembered, that no single science at once bears as strong a relation to, and is so dependent upon, a knowledge of botany, biology, chemistry, mineralogy, physics and astronomy, as is geology. It emphatically furnishes a foundation for them, and in turn must look to them for the interpretation of its data.

By the time a child is of ordinary school age, under such a course of observation, comparison and generalization as the foregoing would suggest, he has formed a habit of being interested in everything about him. If he is a city child, he can have learned all here outlined, or its equivalent; and if a country child, even more, for he is constantly in direct communication with Nature's open album of new and beautiful objects for observation and subjects for reflection.

Continuing our study of stones, we will try the action of water as a solvent. The teacher should place in the pupil's way some varieties, as rock salt, or a hard lump of common salt, which are quickly soluble, alum, not as quickly; a rusty nail that will color the water in a few hours, and the child's own quartz pebbles, insoluble. Call attention to the different actions. With the salt a lesson on saturated solutions may be given. Having shown the effect of water, try acids-strong vinegar or hydrochloric acidupon various stones. Some are unaffected, some hiss a little, some boil violently. Can you see anything passing: off? No. Can you hear anything? Yes; there is a bubbling. What do you see? The bursting of the bubbles. Why do they burst? An invisible gas is passing off. Have you ever seen anything else boil like that in a bottle or a glass? Some pupil will suggest "beer" or "sodawater." Yes, and the same cause produces both; this unseen gas we call carbonic acid gas. Let the pupils taste a little cooled, boiled water, and some fresh, hard, well water. One tastes flat, the other good. The same thing that escaped from the stone, beer and soda water, gives, in the main, the difference of taste between these two waters, viz.: carbonic acid gas. Try more stones with the acid. Some hiss, some do nnt. All that do, have this gas in them, and are called carbonates. Try the acid again on a carbonate. It boils; continue pouring it slowly till boiling ceases. Note the effect; the stone has turned to sandlike particles. Take another carbonate, pour on acid; it boils. Affer a moment pour on some aqua ammonia, the boiling ceases; pour on more, the stone does not crumble. Take a third carbonate; pour on ammonia only. There is no apparent effect. In the first case the stone crumbled; in the second, the crumbling was checked, and in the third, there was no change. Evidently something holds the grains together. What? Some child will say "that gas that blew away." What is it called? What are all such stones called? Drill on this thoroughly. Illustrate solubility and carbonates also by baking soda and cream of tartar. Dissolve a little of each in tumblers of water. Let the pupils taste both in the dry powder. One, soda, is a brackish sweet; the other, tartar, is a definite sour. Pour part of the soda solution into the tartar tumbler ; boiling or effervescence is instæntaneous. Taste the tartar water now. Almost sweet? What has been given off to produce this change? Pour the rest of the soda into some sour milk. It, too, effervesces. Taste it. It is sweetened. The sour substances are acids. This element that sweetens them is an alkali. Ammonia is another alkali. Most alkalies are odorless, and all, if strong, will burn the skin severely. So children should never taste nor play with things in bottles without permission. Give some tiny experiments with heat. Throw several stones into a hot fire. Perhaps some swell up, some grow porous quite rapidly, others more slowly, and some are unchanged. Some change color, and some discolor the flame nearest them-making it yellower. Tell the pupils the explanation of this will come later, but because heat does this sometimes, it is used as a test. As far as possible, always use the children's own stones, and let them, in sections, do the work after you. There will be a little rivalry as to which can do it best and quickest. They will not weary though they see the same thing periormed many times. If certain ones are peculiarly apt, let them, at your order, perform the experiment for the first time. Among the children's fragments there will be a large amount of rubbish. From time to time the teacher can propose "to assort the collections," and casually remark : "So many of these are so nearly alike, which are the most perfect of their kind? Let us lay such aside, and put the rest in a reference pile for a time of need." The plan is readily accepted, the "collections" greatly reduced, and the refuse piled in a corner out of doors, to gradually scatter.

No lessons will be more acceptable to the pupils than those of erosion and sedimentation, taught by calling attention to the water in the streets and gutters after a gentle rain, and after a heavy one, a short one and a protracted one. They will readily see its assorting effect. They will notice the little terraces made, and that the form of these - their comparative width and height-depends upon the velocity as well as amount of water flowing along. Note how they narrow and deepen when passing under crosswalks, and that the current is swifter. Having noted these things, call attention to any ravines, or creeks, or the river and its bank. Show that when a creek widens, the edges, on either side, are apt to be marshy. Why? Notice the different appearances of the bottom. If gravelly, is it clean or dirty? Why? Some pupil goes too near the edge, and the bank caves off. Why? A shrub 
is nearly undermined. Why? Explain how the earth, carried from these parts, is dropped, gradually, farther on.

Thus far our work has been adapted, in the main, to the city pupil with only a limited field for his sand and gravel explorations, the street gutter and an occasional excursion to some picnic ground, a grove and a creek. If a bank of Drift should be at hand, he will have a bonanza for these happy lessons. Pupils will then find some stones with strange markings, suggesting a shell, or one of the corals on the mantel. They have learned to observe and compare, and now draw their own inferences with a certainty that these are shells and corals, in the stones. Is the marking the inside, or outside, of the shell? Is it a complete shell, or only one valve? Did it probably have two valves, like a clam, or was it like a snail, coiled or straight? Teach them to note not only degrees, but kinds of resemblance and difference ; really to distinguish between analogies and homologies. A child often really knows more of a thing than he has the power to tell, unless drawn out by questions. How did these shells and corals come here so high above the water? Mother's shells came from the distant ocean. Once, long, long ago, did the ocean ever come here? and were these alive then? Yes, but they are "fossils," now, petrified thoughts of God, kept all this time for us to study. They are masks without the actors, poems of life written unconsciously. Tell the class something of the habits of similar animals now, enough to stimulate them to further research. Never, by chart, picture or word, tell them directly what they can find out themselves from their own specimens, or walk.s, or speculations. $A l$ ways manifest an interest in every new thing they discover and bring you, however trivial it seems to you. To lead them on, if possible, ask some question the answer to which is not obtained from a casual examination.

With a little plan on the part of the teacher, a very fair working cabinet of the locality may be built up for the school-room. Most children will gladly give their best specimens "for the school," especially if their names may appear as the donors upon the labels. Here they get an idea of permanent labels and how to prepare them.

Before advancing farther, we may note some of the incidental, but not less valuable, benefits to accrue from these studies - not only the habit of interest in common things -habits of observation, investigation, comparison, and classification, but those of industry, honesty, a supreme love for truth, a seeking for it earnestly, and a careful examination as to evidence, also to recognize the fact that one may often, by a single omission, reach a wrong conclusion and have to acknowledge and correct his error. These effects are not immediate, not strikingly apparent, but sure and enduring. I venture to assert that no single study in the usual curriculum of high school and college, aside from the Bible, will more fully fortify against evil influences in youth, adolescence and middle life, and cheer in declining years, than an early, continued and devoutly reverent scientific study, pre-eminently of geology, for it gives constant occupation to the senses and tends inevitably toward the highest and grandest inductions and deductions. The pleasures of observation any and everywhere, of the imagination and of reflection, connected with this science, involving as it does, and must, more or less, all the others, are themselves almost a guarantee against vice. If "the undevout astronomer is mad," much more the undevout geologist, who touches the very handiwork of the great Creator of this and all worlds.

Thus far we have considered Primary and Grammar grade work. In any grade, teacher and student should work together, and with the same great end in view. A stream rises no higher than its source. No extended laboratory is essential and but few instruments, though the more complete the reference library the better. President
Garfield said casually that "a saw-log and the society of Dr. Mark Hopkins was a university of itself," so largely is the student the result of his environment. If he feels in every breath, sees in every act of his professor or teacher, a consecration of energy, a spirit of investigation, a love and zeal for the work, born of intelligent enthusiasm, every latent power in that student's being is, perforce, awakened, and his whole life is aglow with scientific research. Books have their place, and a very large one, yet any geological study founded on book knowledge alone is of little worth. The student must verify for himself, and learn by many mistakes to recognize and interpret the ordinary geologic phenomena of the field and laboratory. The teacher and pupils, with hammer, cold chisel, compass, basket and note-book, and pencil, should go together to the field, the quarry, the ravine, the gravel bank, all these being lacking, to the gutter of the street after a heavy rain, or even to the open prairie. Just the direction of the geologic study, whether structural and physical, or palæontological, must necessarily depend upon the locality of the school. The prime object to be secured is to train pupils to see for themselves, to collect their own data, then study and arrange them, drawing their own deductions. Every teacher should require of the pupils carefully drawn sections or diagrams of this or that special locality, the course of a creek for half a mile, a ravine, a sandpit or a particular quarry. So far as may be, let them be on an approximate scale, giving altitude, thickness, dip and strike of strata, etc. They should also collect any fossils characteristic of the layers, labelling each as from its layer, to avoid confusion in farther study. Having made a number of these investigations, each pupil should compare his or her own papers and specimens one with another, noting down their resemblances and differences, how the strata alter from one layer to another; what fossils are common to all, which abundant, which frequent, which rare; which, whether abundant or rare, are confined to a limited district, etc.

In all science study and teaching our first object should be to be natural. In geology this requires a familiarity with rocks, their form, structure, position and chemical composition. If the course, as previously indicated for primary and grammar grades, has been followed, the student is now ready, with great zeal and profit, to take up more extended field observations, and the regular lecture with a text book. All field study should be followed by a lecture or quizz by the teacher, developing the knowledge of the pupil, and adding to it materially by references, with page and paragraph, to the best authorities, the presentation of charts, pictures, photos, specially illus trative specimens, chemical experiments, etc. Far better results are obtained if, under each head, some single illustration is taken and traced as far as possible. For instance, under igneous agencies take Vesuvius, giving every thing that can be gathered, its cone, materials erupted, and their amount, the buried cities,-include, it may be, even some poetic references. Then will naturally follow the kinds of volcanoes, their location, age, the theories of their origin, and earthquakes and their phenomena. Under aqueous agencies nothing can be more stimulating and convincing than a study of our own Mississippi River, as fully described by Abbott and Humphrey. Let the pupil identify all he can. For erosive action of water on a large scale take Niagara. For both erosion and sedimentation, on a very small but quite as true a scale, take a city gutter, near its source and at its outlet. Present one typical illustration under each head so fully that it will be a standard for the pupil in all similar processes, whether in field, laboratory or class room.

In our own section, about Rockford, Ill., we have the Galena Division of the Trenton, outcropping in various 
places along Rock River, and exposed in many railroad cuts. While the general exposure is only of the yellow or buff stone, in several localities it has been quarried down to the blue. With a piece of each color in hand, and the quarry itself under close inspection, a valuable series of facts may be discovered by the pupils-the strata joints, seams, etc., whether they are equally distinct in all parts of the exposure, whether adjoining strata are decided contrasts; if so, in what respects, color, texture, homogeneity, hardness, etc. Enquire which strata are the oldest, and why so decided? Which strata are best adapted to the purpose of quarrying? As a building stone, will it be greatly affected by water? Weigh a fragment in its natural condition; dry it as fully as possible and weigh again,-a druggist's scales will give the change. Judging from various exposures, does the stone "weather" smooth or in depressions? Can you tell the original upper surface of a flagging stone from the lower? How? In building, is it better to "lay" the stone with any reference to this original surface? Why? With a hand magnifier of ordinary power, examine the texture of the rock, coarse or fine? Are there occasional little "pockets" in it? Is the sand in these the same as in the rock itself? Those white, irregular stones, imbedded here and there, what are they, and how do they differ from the others? They are flint or quartz,-strike them sharply with a piece of steel,- - fire flies. What are those little brick-red masses here and there? How do they differ in texture and shape of grains? Is the rock firmer or less firm in their vicinity? They are iron nodules. Are they beneficial? Why? Note the reddish powder around any nodule, if kept damp, and how the stone streaks. What other forms have you found? An incrustation? Yes. Touvertine, a deposit of carbonate of lime from the water trickling among the strata. How do you know it is a carbonate? This time try nitric acid instead of hydrochloric on these peculiar forms, carbonate, quartz and iron,- - note the difference of action. In this way a thousand things familiar to every geologist will be learned by the student, and bring to him the inspiration of a discovery,

The pupils have gathered all the fossils they could, whether many or few. Some are manifestly corals and a form allied, fossil sponges; others are shells. Separate them. What do they suggest as to the origin of the rocks? Where were they formed? Are they more closely allied to salt or fresh water species? Examine carefully the valves, hinge line, ribs or striæ, beals and umbo, sinus and folds. Find specimens giving both internal and external structures or characteristics, if you can. Distinguish between a cast and the fossil itself. Are the casts of any value? What? Classify, as well as may be, all the fossils collected, according to form and according to internal structure, so far as it can be traced. Not all shells that look similar on the outside belong to the $\operatorname{sam} \theta$ genus, nor do all belonging to the same genus look alike, necessarily. After the student has made a goodly collection of fossils and facts about them, the teacher may lead him on, with State Reports and other authorities, till the final identification is reached, but the pupil should take every step himself for himself, when able. In all these lectures and quizzes, the blackboard is an invaluable help, making diagrams as you progress, rather than present a more perfect one, completed before the class enters.

At Rockford, also, we have a fair exposure of the Drift. After studying the stratified rocks as such, the class is ready to study stratification as presented here, and to make further maps or diagrams. Note the sizes of the gravel stones and their arrangement. Is there a regularity in distribution as to size of pebbles? Few better fields in a prairie section can be found for the varied forms of quartz. Occasionally bits of mineral are found, -galena and copper,-the former suggesting the mining districts of Northern Illinois and Southern Wisconsin; the latter, from its form, the Lake Superior region. Fossils of various kinds are not infrequent, but of genera and species quite different, usually, from those found in the quarries and railroad cuts. The drift has brought them from several formations and from long distances. Often the internal and external structures of these specimens are better preserved than in those imbedded in the rock. Indeed, most of the best and most exact descriptions of palæozoic corals have been based upon drift specimens. The pupils having made collections of the different varieties of rock from the drift, the teacher may here give some ready tests of identification for common forms, or some simple mineralogical table. We have few bowlders, but those few, with the drift rocks, submit themselves to the same kind of study as rocks in situ, whether macroscopic, microscopic, or chemical, so are well adapted to all petrographic study, save geographical limits.

At Rockford we have the deep, heavy prairie deposit, black as are all rich soils due to the decay of vegetable substances. If this soil is burned, there is little change, save in color,- the mass is argillaceous matter, with a little fine sand. The stratification noticed in the walls of wells, and in artesian well borings suggests the same agency as the quarry and the drift, viz.: water; but the occasional shell fragments found bear little resemblance to those in the quarry, rather to our fresh-water Unio, Anadonta and Paludina, genera still living in the rivers and marshes. The inference, then, is that at some remote time, but later than the quarry and the drift with their salt-water fauna, there was a fresh-water lake, perhaps an arm of Lake Michigan, reaching out toward the Mississippi River, or the Mississippi extended this way.

As the conservation of energy has given us a new physics, so the microscopic study of rocks and fossils has given us a new geology. Though microscopic rock-sections were first made in 1854, it was not until they were introduced into Germany a few years ago, that they became an active agent in geologic research. Only by this careful method can these petrified thoughts of the Creator be fully understood. Palæontology is essentiallybiological, dealing with the plants and animals on the globe rather than with the life of the globe, but it has rendered an inestimable service in determining the question of evolution, so the microscopic section will be of inestimable service to the petrographer with his crystalline rocks, whether volcanic, plutonic or metamorphic. For making these sections let the pupils use their own ingenuity in preparing the simple apparatus really essential. If a section cutter is at hand of approved pattern, or an electric or foot-power lathe, very well; but if not, it is just as well, for with cold chisel, hammer and file, the student can easily reduce his specimen to a proper size for grinding. The superficial surface may be as large as preferred, but the tbickness not more than one-fourth inch, if the intention is to make a translucent slide. If only one surface is to be ground, the only care will be to get the angle desired for the examination. For early work only calcareous specimens should be used. Let the student furnish himself with a plate $12 \times 16$ inches of floor glass, smooth on one or both sides; a half-dozen pieces of double or treble thick glass $2 \times 2$ inches, a half-dozen spring clothes pins, emery of 4-7 grades, the finest being emery "slime;" a piece of chamois skin, stretched tightly over a smooth board to polish upon; some Canada balsam, hard and soft; some alcohol, a lamp and some matches, and a little water. With a few needles in wooden handles, and a firm table to work upon, he is independent of surrounding:s. His patience, time and skill will be taxed, but these are the 
wrapping paper and cord to secure this trophy of the past, and draw from it its inmost secrets. The grinding is simply friction with emery and water till the first face ts prepared, and polished on the chamois skin with $d r y$ emery slime. This should be as perfectly done as possible. The specimen may be considered as finished at this stage, if no complete examination of structures is intended, no tracing of homologies in various genera and species. If this exact study is to be prosecuted, on one of the small glass pieces, polished surface down, imbed the specimen in balsam, just hard enough and deep enough to securely hold it, but not so hard as to crack off, as the grinding of the second surface advances. Care must be taken to hold the glass horizontally, lest the specimen be of unequal thickness at the close. When nearly translucent, great care must be taken by grinding lightly and more and more lightly, till the work is complete and the polishing done. Warm the balsam which still holds it to the glass, and delicately slide the well-earned treasure to a new microscopic slide, $1 \times 3$ inches, on which is a drop of hot balsam. This successfully done, remove any air bubbles and lay on the cover glass, removing bubbles again. Clamp it with a clothes pin till dry and cold, then remove all surplus balsam with turpentine, taking care that it does not also run under the cover glass. It is now ready for study. When several specimens of different species or "genera of Rugosa, for instance, have been made, fine lessons may be drawn in homologies, especially of mural, septal and tabular systems.

As the large majority of students will not carry their scientific studies, as such, farther than the requirements of the college curriculum, it is eminently important that their attention be called all along to certain prominent things as prominent, as the great questions to be sought out. In giving these special points of the field in general, the teacher or professor will naturally present in a more extended way that special field which has most attracted his or her own attention or investigation. For reference and for present benefit the pupils should each, under the eye of the teacher, make a geological map of the United States; one of his own state on a larger scale, and of his own section on a still larger one. He should also number carefully and permanently his specimens, using a tiny circle of paper and glue unaffected by ordinary moisture, these numbers corresponding to those on labels bearing name of formation, group, genera and species, with the date and locality.

In preparing this paper I have been painfully conscious of its inadequacy and its great imperfections, yet from experience and observation I hope to have measured an arc in the circle of scientific and geologic education in our schools whose circumference may be eventually completed.

\section{LETTERS TO THE EDITOR.}

** Correspondents are requested to be as brief as possible. The writer's name is in all cases required as a proof of good faith.

On request in advance, one hundred copies of the number containing his communication will be furnished free to any correspondent.

The editor will be glad to publish any queries consonant with the character of the journal.

\section{AN INSTRUCTIVE ILLUSION.}

ON Thursday evening, May 18th, occurred at York one of those smart thunder-showers which followed the breakup over the greater part of England of the sunniest, warmest and driest spring within the memory of most. Hail had fallen, and five minutes later, at 6.50, clear sky appeared among the storm-clouds. Not quite clear, however, for it was flecked with those very delicate, filmy, white clouds which one usually assigns to a very lofty altitude. The sun being within an hour of setting, its slanting rays illuminated these strongly. It was therefore with surprise that I saw shoot athwart these sharply-defined, intensely dark bars of shadow. These evidently came from a portion of cumulus-like thunder-cloud, which topped the main mass just below and to the right of the new moon. Some of the rays sprang direct from its edge, but others at a distance of $2^{\circ}$ to $10^{\circ}$. In the shadow the filmy clouds were absolutely invisible, the sky seemingly being of a clear blue, although the shifting of the bars of shadow indicated their actual presence everywhere.
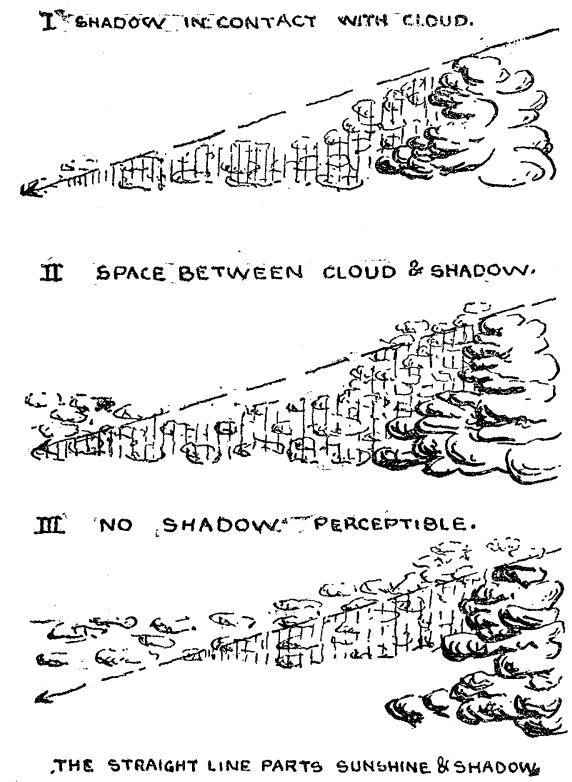

But the strange question arises, what was the real height of the film-clouds? Must they not, obviously, have been at a lower level than this portion of the thunder-cloud, though higher than the main mass? And yet portions must have been piled higher against the thunder-cloud. Else there could not have been the illuminated space dividing the shadow from the cloud. In some cases the dark bars merged into sheets of shadow, which stretched away $20^{\circ}$ or more from the cloud. Apparently, if seen in section, the effect must have been as in the appended sketches.

It is difficult to conceive any other explanation than the above. Hence, either such film-clouds form at lower levels than is generally supposed, or the summits of thunder-clouds penetrate higher than has been supposed. J. Edmund Clark.

Why NOT THE COLLECTIONS OF SEEDS?

IN these days of stamp, coin, shell, mineral, plant and insect collectors, the writer has often wondered why it is that so few have turned their attention to making collections of seeds. The field, as it appears to me, is one of exceptional interest; exceptional not merely because of the work of real merit that may be done therein, but because it is practically inexhaustible; because the materials are very largely of such a nature as to be cared for with a minimum amount of labor, and require but little space; and because in many instances seeds are themselves objects of great beauty. There are few pursuits in which greater latitude may be allowed, or greater opportunity is given for display of individual energy and mental scope. The amateur, whether man or woman, boy or girl, business man or teacher, cripple or invalid, may each and all collect and find ample room for so much or so little study as he or she may choose to devote to it. One may collect only such seeds as have in 